\title{
AVALIAÇÃO DA ATIVIDADE ANTIMICROBIANA DO \\ EXTRATO BRUTO ETANÓLICO DE Magonia pubescens
}

\section{ST.HIL. (SAPINDACEAE)}

Fabiana Cristina Pimenta, ${ }^{\prime}$ Heloisa Helena Garcia da Silva,' Izabel Yoko Ito, ${ }^{2}$ Viviany Pires Guimarães ${ }^{3}$ e Ionizete Garcia da Silva ${ }^{1}$

\section{RESUMO}

A atividade antimicrobiana do extrato bruto etanólico (e.b.e.) da Magonia pubescens foi testada para cepas de Micrococcus luteus (ATCC 9341), Staphylococcus aureus (ATCC 25923), Enterococcus faecalis (ATCC 10451), Escherichia coli (ATCC 25922), Pseudomonas aeruginosa (ATCC 15442), Candida albicans (ATCC 1023), S. aureus penicilinase positivo, $S$. aureus penicilinase negativo, $S$. aureus oxacilina resistente, S.epidermidis, S. aureus, Streptococcus mutans e $S$. sobrinus (cepas isoladas de espécimes clínicos), pela técnica de difusão em ágar, empregando-se o método de poço em camada dupla. A concentração inibitória mínima (CIM) do e.b.e. da $M$. pubescens foi determinada para estafilococos coagulase negativos ( $\mathrm{SCN}$ ) e para $S$. aureus. O extrato etanólico bruto de M. pubescens mostrou atividade antimicrobiana para Staphylococcus e para $C$. albicans $e$ ausência de atividade para Streptococcus e bactérias Gram-negativas. Dentre os 25 estafilococos testados, três $(12,0 \%)$ apresentaram CIM de $10,0 \mu \mathrm{g} / \mathrm{ml}$, sendo todos SCN produtores de penicilinase e resistentes à oxacilina. Dezesseis $(64,0 \%)$ cepas apresentaram CIM de $1,25 \mu \mathrm{g} / \mathrm{ml}$, compreendendo cinco (31,3\%) S.aureus e onze $(68,7 \%)$ SCN. A menor concentração de e.b.e. capaz de inibir seis cepas de estafilococos foi de $0,625 \mu \mathrm{g} / \mathrm{ml}$. Os $\mathrm{SCN}$ foram inibidos em concentraçð̃es mais elevadas do e.b.e. dessa planta quando comparados com os S.aureus. A M. pubescens apresentou atividade antimicrobiana para bactérias Gram-positivas, inclusive estafilococos multirresistentes e $C$. albicans, sugerindo seu emprego como anti-séptico ou desinfetante. Entretanto, outras análises devem ser realizadas.

UNITERMOS: Magonia pubescens. Atividade antimicrobiana.

1 Instituto de Patologia Tropical e Saúde Pública (IPTSP) da Universidade Federal de Goiás (UFG), Goiânia, Goiás.

2 Faculdade de Ciências Farmacêuticas de Ribeirão Preto (FCFRP) da Universidade de São Paulo (USP), Ribeirão Preto, São Paulo.

3 Mestranda do Programa de Pós-Graduação em Medicina Tropical, IPTSP/UFG.

Endereço para correspondência: Rua Delenda Rezende de Melo esq. com $1^{\text {a }}$ Avenida, Setor Universitário. Caixa Postal 131, CEP 74605-050, Goiânia, GO. E-mail: ionizete@iptsp.ufg.br

Recebido para publicação em 11/3/2000. Revisto em 5/4/2000. Aceito em 18/5/2000. 
A fitoterapia representa uma das práticas mais antigas da humanidade, com o emprego de plantas para diversos propósitos terapêuticos, como no tratamento de processos inflamatórios, infecções, lesões de pele, diarréia, doenças venéreas, picadas de insetos etc. (Samy et al., 1998). O seu uso tanto para o tratamento de enfermidades de origem bacteriana quanto fúngica e viral tem sido realizado, desde a mais remota antigüidade, ou seja, muito antes da identificação dos agentes etiológicos (Silva, 1992).

Nos países industrializados, aproximadamente $25 \%$ dos medicamentos prescritos e registrados contêm fármacos ativos derivados de vegetais (Arnason et al., 1994). Entretanto, nos países em desenvolvimento, cerca de $75 \%$ da população depende da medicina alternativa para solucionar seus problemas de saúde, devido ao alto custo da terapêutica convencional (Ahmad et al., 1998). Na maioria das vezes, as pessoas se utilizam de plantas sem nenhum embasamento científico, prática que pode resultar em intoxicações e em outros distúrbios. No Brasil, esta realidade é agravada pelas diversidade e abundância de espécies vegetais desconhecidas tanto química como taxonomicamente (Arnason et al., 1994).

A partir da década de 1930, com o aumento do processo de síntese de substâncias anteriormente extraídas da natureza, a terapia alternativa com plantas perdeu um pouco a sua importância (Silva, 1992), ressurgindo apenas nas últimas duas décadas, devido ao fato de muitos fármacos, mesmo os de última geração, apresentarem um espectro de ação limitado, efeitos colaterais e promoverem a seleção de cepas microbianas resistentes (Rizvi et al., 1987). De acordo com Marangoni (1996), cepas de $S$.aureus meticilina resistentes (MRSA) e estafilococos coagulase negativos meticilina resistentes (MRSCN) também estão sendo detectados na comunidade. Mian et al. (1999), por exemplo, isolaram $83(48,0 \%)$ cepas de Staphylococcus aureus da saliva de 173 indivíduos saudáveis atendidos em uma clínica odontológica. Destas, 61 $(73,5 \%)$ produziram penicilinase e $23(27,7 \%)$ apresentaram resistência à oxacilina, concluindo que o isolamento de MRSA em 23 indivíduos saudáveis representa um elevado risco, uma vez que esses portadores podem disseminar a bactéria tanto em consultórios e/ou clínicas, como na comunidade.

Ahmad et al. (1998) relataram que na Índia uma grande porção da população utiliza plantas medicinais, devido à sua efetividade, ao seu baixo custo e aos poucos efeitos colaterais. Assim, avaliaram a atividade antimicrobiana de extratos aquosos, alcoólicos e com hexano de 82 plantas utilizadas na Índia, diante de seis bactérias (Bacillus subtilis, Proteus vulgaris, Salmonella typhimurium, Pseudomonas aeruginosa, Escherichia coli $\mathrm{K} 12, S$. aureus). Desse total de plantas, 56 apresentaram atividade contra 
um ou mais patógenos testados, sendo que cinco plantas com amplo espectro de ação (Emblica officinalis, Terminalia chebula, Terminalia belerica, Plumbago zeylanica, Holarrhena antidysenterica).

Samy et al. (1998) também avaliaram a atividade antimicrobiana de 34 plantas, pertencentes a 18 famílias, empregadas pela população indiana, e os microrganismos empregados foram E. coli, Klebsiella aerogenes, Proteus vulgaris e $P$. aeruginosa. Das 34 plantas analisadas, 16 apresentaram atividade antimicrobiana, sendo que três (Cassia fistula, Terminalia arjuna, Vitex negundo) mostraram uma significativa atividade, confirmando a eficácia do uso. De acordo com Cowan (1999), nos Estados Unidos a popularidade e as vendas de produtos de origem vegetal aumentaram $37 \%$ após 1995 .

Dessa forma, a fitoterapia volta a ganhar uma inequívoca importância, com vários pesquisadores se dedicando ao estudo de vegetais utilizados na medicina popular, e assim sendo possível traçar o perfil químico, toxicológico, farmacológico e antimicrobiano das plantas estudadas (Arnason et al., 1994). O cerrado brasileiro possui um flora muito rica e muitas das suas plantas, na maioria das vezes, são utilizadas de forma empírica, no controle de infecções, podendo ser uma alternativa para as classes sociais de baixa renda.

A $M$. pubescens é uma planta típica de cerrado, pertence à família Sapindaceae e pode ser caracterizada como uma árvore de porte médio, que atinge entre 5 e 9 metros de altura, possui folhas paripenadas, com 3 a 6 pares de folíolos glabros, medindo de 3 a $6 \mathrm{~cm}$ de comprimento por 3 a $5 \mathrm{~cm}$ de largura. Floresce nos meses de agosto e setembro, e a maturação dos frutos ocorre após 12 meses. A distribuição geográfica da planta é predominante na região central do Brasil - em Goiás, Mato Grosso, Mato Grosso do Sul e Minas Gerais (Joly, 1967; Lorenzi, 1992).

Silva et al. (1996), demonstrando a atividade larvicida do e.b.e. da M. pubescens para o Aedes aegypti, principal vetor de dengue e febre amarela, relataram também que a população da Região do Centro-Oeste do Brasil utiliza, com sucesso, uma mistura de água e casca/entrecasca dessa planta para tratamento de feridas no gado bovino. Este fato estimulou a realização de bioensaios para verificar a atividade antimicrobiana dessa planta. Considerando, portanto, que o cerrado brasileiro possui riqueza e variedade de plantas com atividade fitoterápica que precisam ser estudadas, realizou-se, então, um trabalho com o objetivo de verificar a atividade antimicrobiana do extrato bruto etanólico (e.b.e.) da $M$. pubescens para cepas de Micrococcus luteus, Staphylococcus aureus, $S$. aureus penicilinase positivo, $S$. aureus penicilinase negativo, $S$. aureus oxacilina resistente, $S$. epidermidis, S. aureus, Streptococcus mutans, S. sobrinus, Enterococcus faecalis, Escherichia coli, Pseudomonas aeruginosa e Candida albicans. 
O extrato bruto etanólico (e.b.e.) da $M$. pubescens foi obtido da casca do caule, da semente e da raiz, no Laboratório de Bioatividade de Plantas do Instituto de Patologia Tropical e Saúde Pública da Universidade Federal de Goiás (IPTSP-UFG). As partes eram dessecadas em estufa de ventilação forçada à temperatura de $40^{\circ} \mathrm{C}$, moídas e percoladas a frio por 72 horas em becker protegido da luz com papel alumínio, usando etanol como solvente. Em seguida, eram feitas a filtragem em papel-filtro qualitativo, e a concentração, em evaporador rotativo. $\mathrm{O}$ e.b.e. obtido foi secado em capela de exaustão à temperatura ambiente, acondicionado em frascos de vidro, coberto com papel alumínio perfurado, até a completa evaporação do solvente e estocado em dessecador até a utilização (Silva et al., 1996).

A atividade antimicrobiana do e.b.e. da $M$. pubescens foi determinada pela técnica de difusão em ágar, empregando-se o método de poço em camada dupla (Grove \& Randall, 1955) diante de vários microrganismos-padrão e cepas isoladas de espécimes clínicos (Micrococcus luteus ATCC 9341, S. aureus ATCC 25923, S. aureus penicilinase positivo, $S$. aureus penicilinase negativo, $S$. aureus oxacilina resistente, $S$. epidermidis, Streptococcus mutans, S. sobrinus, Enterococcus faecalis ATCC 10451, E. coli ATCC 25922, E. coli, Pseudomonas aeruginosa ATCC 15442 e C.albicans ATCC 1023). Os testes da atividade antimicrobiana foram realizados, em triplicata, no Laboratório de Microbiologia (Departamento de Bromatologia, Toxicologia e Análises Clínicas) da Faculdade de Ciências Farmacêuticas de Ribeirão Preto - USP.

Os inóculos foram preparados utilizando cultura de 24 horas a $37^{\circ} \mathrm{C}$ em meio Mueller Hinton Broth (MHb) - Difco ou Brain Heart Infusion (BHI) - Difco, conforme as exigências nutritivas dos microrganismos. A camadabase foi obtida com 10,0ml de MHa (Mueller Hinton Medium - Difco) ou BHIa (Brain Heart Infusion Agar - Difco). Após a solidificação foram adicionados $5,0 \mathrm{ml}$ de inóculo bacteriano obtido pela adição de $0,25 \mathrm{ml}$ de uma suspensão bacteriana contendo entre $10^{6}$ a $10^{7} \mathrm{ufc} / \mathrm{ml}$ em meio $\mathrm{MHa}$ ou BHIa à cerca de $50^{\circ} \mathrm{C}$, sendo todas as placas preparadas em triplicata. A seguir, foram confeccionados orifícios de $5,0 \mathrm{~mm}$ de diâmetro em pontos eqüidistantes.

Alíquotas de $20,0 \mu \mathrm{L}(400 \mu \mathrm{g})$ do e.b.e. da $M$. pubescens foram colocadas em cada um dos poços com o auxílio de uma pipeta automática. As placas foram pré-incubadas à temperatura ambiente, durante duas horas e depois incubadas a $37^{\circ} \mathrm{C}$, cerca de 24 horas. Decorrido o período de incubação, as zonas de inibição foram mensuradas com o auxílio de régua milimetrada, em termo de aro (da borda do poço ao início do desenvolvimento microbiano) e halo (diâmetro da área com ausência de desenvolvimento microbiano). 
A determinação da Concentração Inibitória Mínima (CIM) do e.b.e. da $M$. pubecens para cepas de estafilococos foi feita pelo método de diluição em ágar recomendado pelo National Committee for Clinical Laboratory Standards-NCCLS (1998). A CIM do e.b.e. da M. pubescens foi determinada diluindo-se $1,6 \mathrm{mg}$ do e.b.e. em $8,0 \mathrm{ml}$ de água destilada. A partir desta suspensão $(200 \mu \mathrm{g} / \mathrm{ml})$ foram realizadas diluições duplas até $0,156 \mu \mathrm{g} / \mathrm{ml}$, adicionando-se ágar Mueller Hinton em quantidade suficiente para obter o volume de $20,0 \mathrm{ml}$, ou seja, na concentração final de $20,0 \mu \mathrm{g} / \mathrm{ml}$ até $0,0156 \mu \mathrm{g} / \mathrm{ml}$, homogeneizado e vertido em placas de Petri esterilizadas. Todas as diluições foram feitas em duplicatas.

As 25 cepas de Staphylococcus sp. testadas foram isoladas das mãos e nariz de profissionais da saúde de Goiânia, Goiás, empregando ágar manitol e mantidas em caldo nutriente acrescido de glicerol e conservado a $-10^{\circ} \mathrm{C}$ no Laboratório de Bacteriologia Médica do IPTSP - UFG. Essas cepas foram identificadas de acordo com a morfologia colonial macroscópica, coloração de gram, fermentação do manitol, produção da coagulase e lecitinase e penicilinase ou $\beta$-lactamase (Konemann et al., 1993). A resistência à oxacilina foi determinada pelo método de triagem em ágar oxacilina (NCCLS, 1998). Os estafilococos foram repicados em ágar Mueller Hinton e incubadas a $37^{\circ} \mathrm{C}$ por 24 horas. Os inóculos foram preparados em $5,0 \mathrm{ml}$ de solução salina, esterilizada até a obtenção de uma turvação equivalente a metade da escala 1 de McFarland, transferidos para o inoculador de Steers (Steers et al., 1959) e aplicados nas superfícies das placas de ágar Mueller Hinton, contendo as diferentes concentrações do e.b.e. da planta. As placas foram incubadas a $37^{\circ} \mathrm{C}$ por 24 horas. Considerou-se CIM a menor concentração do extrato que inibiu o desenvolvimento microbiano.

\section{RESULTADOS E DISCUSSÃO}

Neste estudo, verificaram-se, pelo método de difusão de poço a atividade antimicrobiana do e.b.e. da $M$. pubescens, para o Micrococcus luteus, para o Staphylococcus (bactérias Gram-positivas) e para o C. albicans, e a ausência de atividade contra Streptococcus e bactérias Ml (Tabela 1). Analisando-se o tamanho dos halos e aros, observou-se que não houve variações significativas nas medidas, sendo essas dimensões similares para os diferentes microrganismos testados. Ressalta-se a atividade antimicrobiana do e.b.e. da $M$. pubescens observada diante dos estafilococos, em especial com relação ao estafilococo oxacilina resistente e à $C$. albicans. Os resultados satisfatórios da atividade antimicrobiana diante de bactérias Gram-positivas sugerem a purificação do extrato etanólico com a realização de outros testes com diferentes concentrações e frações cromatográficas. Assim, estes resultados mostram que, além da atividade biocida da $M$. pubescens para o $A$. aegypti (Silva et al., 1996), o extrato também apresenta atividade 
antimicrobiana para estafilococos e $C$. albicans. Fato importante é que a $M$. pubescens pode ser utilizada para vários propósitos, corroborando o achado de Vaidya (1994), com a Terminalia arjuna, que apresenta atividades antiinfecciosa e cardiotônica.

Após a deteç̧ão da atividade antimicrobiana da $M$. pubescens, pelo método de difusão em ágar, realizou-se a determinação da concentração inibitória mínima (CIM) diante de 25 cepas de estafilococos (Tabela 2). Destas cepas, nove $(36,0 \%)$ foram identificadas como $S$. aureus, sendo sete $(77,8 \%)$ produtoras de penicilinase e duas $(22,2 \%)$ resistentes à oxacilina. Dentre as 16 cepas caracterizadas como estafilococos coagulase negativos (SCN), $14(87,5 \%)$ produziram penicilinase e $12(75,0 \%)$ se mostraram resistentes à oxacilina, sendo denominados de estafilococos oxacilina/meticilina resistentes (ORS), ou seja, estafilococos considerados multirresistentes.

Silva (1992) avaliou a atividade antimicrobiana, pelo método de difusão em ágar (disco e poço) de extrato bruto e frações de três plantas, da família Convolvulaceae, empregadas na medicina popular nordestina (Ipomoea cairica, I. pes-caprae, I. phyllomega) diante de vários microrganismos indicadores. Mostrou que a I. cairica apresenta uma melhor atividade antimicrobiana, e que as bactérias Gram-negativas foram mais sensíveis do que as Gram-positivas ao extrato acetatoetílico, enquanto que duas frações desta planta (SP-1 e SP-2) apresentaram maior atividade para as bactérias Gram-positivas. Concluiu que os resultados corroboram a sabedoria e o emprego popular de algumas espécies de Ipomoea como agentes antinfecciosos.

Tabela 1. Atividade antimicrobiana do extrato bruto etanólico de Magonia pubescens determinada pelo método de difusão em ágar

\begin{tabular}{lcc}
\hline Microrganismo & Aro ${ }^{*}(\mathrm{~mm})$ & Halo $^{*}(\mathrm{~mm})$ \\
\hline Micrococcus luteus (ATCC 9341) & 4 & 13 \\
Staphylococcus aureus (ATCC 25923) & 3 & 13 \\
Staphylococcus aureus penicilinase positivo & 3 & 12 \\
Staphylococcus aureus penicilinase negativo & 3 & 12 \\
Staphylococcus aureus oxacilina resistente & 2 & 10 \\
Staphylococcus epidermidis & 4 & 14 \\
Streptococcus mutans (espécime clínico) & 0 & 0 \\
Streptococcus sobrinus (espécime clínico) & 0 & 0 \\
Enterococcus faecalis (ATCC 10451) & 0 & 0 \\
Escherichia coli (ATCC 25922) & 0 & 0 \\
Escherichia coli (espécime clínico) & 0 & 0 \\
Pseudomonas aeruginosa (ATCC15442) & 0 & 0 \\
Candida albicans (ATCC 1023) & 4 & 14 \\
\hline
\end{tabular}

Legenda: * média dos valores obtidos pela realização de três testes (triplicata); 0: ausência de atividade. 
A medicina popular fornece informações muito importantes para a seleção de plantas com atividade terapêutica. A avaliação da atividade antimicrobiana in vitro de extratos de plantas e agentes químicos tem sido realizada desde o início da era microbiana (Silva, 1992).

Tabela 2. Concentração inibitória mínima do extrato bruto etanólico da Magonia pubescens, produção de penicilinase e sucetibilidade a oxacilina de cepas de Staphylococcus

\begin{tabular}{llccc}
\hline Cepa & Espécie & Penicilinase & Oxacilina & CIM $(\mu \mathrm{g} / \mathrm{ml})$ \\
\hline 1 & Staphylococcus aureus & + & $\mathrm{S}$ & 1,250 \\
2 & Staphylococcus aureus & + & $\mathrm{S}$ & 0,625 \\
3 & Staphylococcus aureus & + & $\mathrm{S}$ & 0,625 \\
6 & Staphylococcus aureus & - & $\mathrm{S}$ & 1,250 \\
7 & Staphylococcus aureus & - & $\mathrm{S}$ & 0,625 \\
8 & Staphylococcus aureus & + & $\mathrm{S}$ & 1,250 \\
13 & Staphylococcus aureus & + & $\mathrm{S}$ & 1,250 \\
24 & Staphylococcus aureus & + & $\mathrm{R}$ & 0,625 \\
29 & Staphylococcus aureus & + & $\mathrm{R}$ & 1,250 \\
4 & SCN & - & $\mathrm{S}$ & 1,250 \\
9 & SCN & + & $\mathrm{R}$ & 1,250 \\
10 & SCN & + & $\mathrm{R}$ & 1,250 \\
12 & SCN & + & $\mathrm{S}$ & 0,625 \\
14 & SCN & + & $\mathrm{R}$ & 1,250 \\
15 & SCN & + & $\mathrm{R}$ & 10,000 \\
17 & SCN & + & $\mathrm{R}$ & 0,625 \\
18 & SCN & + & $\mathrm{R}$ & 10,00 \\
19 & SCN & + & $\mathrm{R}$ & 10,00 \\
20 & SCN & + & $\mathrm{R}$ & 1,250 \\
22 & SCN & + & $\mathrm{S}$ & 1,250 \\
23 & SCN & + & $\mathrm{R}$ & 1,250 \\
25 & SCN & - & $\mathrm{S}$ & 1,250 \\
26 & SCN & + & $\mathrm{R}$ & 1,250 \\
27 & SCN & + & $\mathrm{R}$ & 1,250 \\
28 & SCN & + & $\mathrm{R}$ & 1,250
\end{tabular}

Legenda: SCN: estafilococos coagulase negativos; +: produtor; -: não produtor; S: sensível; R: resistente

Dentre os 25 estafilococos testados (Tabela 2), três (12,0\%) apresentaram CIM de $10,0 \mu \mathrm{g} / \mathrm{ml}$, sendo todos SCN produtores de penicilinase e resistentes à oxacilina (cepas 15, 18 e 19). Dezesseis $(64,0 \%)$ cepas apresentaram CIM de $1,25 \mu \mathrm{g} / \mathrm{ml}$, compreendendo cinco $(31,3 \%) S$. aureus e onze $(68,7 \%) \mathrm{SCN}$. A menor concentração do extrato de $M$. pubescens capaz de inibir seis estafilococos - quatro (66,7\%) S.aureus e dois 
$(33,3 \%) \mathrm{SCN}$ - foi $0,625 \mu \mathrm{g} / \mathrm{ml}$. Assim, os $\mathrm{SCN}$ foram inibidos em concentrações mais elevadas do e.b.e. da $M$. pubescens com exceção das cepas 12 e 17, enquanto que os $S$. aureus foram inibidos em menores concentrações.

$\mathrm{O}$ controle de infecção tornou-se um dos maiores desafios, em virtude da incidência de microrganismos multirresistentes e de pacientes imunocomprometidos, o que tem levado à busca de terapias alternativas, como a fitoterapia. $\mathrm{O}$ estudo dos vegetais poderá permitir a deteç̧ão de compostos ativos contra os microrganismos (Cowan, 1999), como no caso da atividade antimicrobiana do e.b.e. da $M$. pubescens para diferentes microrganismos, bem como para estafilococos multirresistentes, a qual tem se mostrado muito promissora e de certa forma comprovado a sabedoria popular. Novas análises de atividade antimicrobiana, no entanto, devem ser realizadas, empregando-se outros microrganismos e extrato bruto purificado na tentativa de determinar a fração ativa.

AGRADECIMENTOS

Apoio financeiro: FUNAPE, Proc. 272; CNPq/RHAE, Proc. 610100/95-5

\section{SUMMARY}

Antimicrobial activity of the Magonia pubescens St.Hil. ethanolic extract

The antimicrobial activity of the ethanolic extract of the Magonia pubescens was determinated for Micrococcus luteus (ATCC 9341), Staphylococcus aureus (ATCC 25923), Enterococcus faecalis (ATCC 10451), Escherichia coli (ATCC 25922), Pseudomonas aeruginosa (ATCC15442), Candida albicans (ATCC 1023), penicilinase positive $S$. aureus, penicilinase negative $S$. aureus, oxacillin resistante $S$. aureus, $S$. epidermidis, $S$. aureus, Streptococcus mutans, $S$. sobrinus (clinical strains) by agar diffusion assay. The minimum inhibitory concentration (MIC) of the ethanolic extract was determinated against coagulase negative staphylococci (SCN) and Staphylococcus aureus. The M. pubescens inhibited the Micrococcus luteus, Staphylococcus and the Candida albicans, but the streptococci and Gramnegative rods were not inhibited. Three (12.0\%) SCN showed MIC of $10.0 \mu \mathrm{g} / \mathrm{mL}$, produced penicilinase and were oxacilin resistant. Sixteen strains presented MIC of $1.25 \mu \mathrm{g} / \mathrm{mL}, 5(31.3 \%)$ S.aureus and $11(68.7 \%) \mathrm{SCN}$. The lowest concentration of the ethanolic extract capable of inhibition was $0.625 / \mathrm{mL}$. The SCN were inhibited in higher concentration of the ethanolic extract than $S$. aureus. This study notes that the ethanolic extract of $M$. pubescens presents antimicrobial activity against Gram-positive bacteria, including multiresistant staphylococci and $C$. albicans. However, the use of this substance as an antiseptic or desinfectant warrants further research.

KEYWORDS: Magonia pubescens. Antimicrobial activity. 
1. Ahmad I, Mehmood Z, Mohammad F. Screening of some indian medicinal plants for antibacterial properties. J Ethonophar 62:173-182, 1998.

2. Arnason JT, Mata R, Romero JT. Proceedings of the thirthy fourth annual meeting of the phytochemical society of North America on phytochemistry of medical plants. $1^{\text {a }}$ Ed., New York, Ed. Plenum Press, 1994, p.363.

3. Cowan MM. Plant products as antimicrobial agents. Clin Microbiol Rev, 12:564-582, 1999.

4. Grove, D.C.; Randall, W.A. Assay methods of antibiotics: a laboratory manual. New York: Medical Encyclopedia Inc, 1955.

5. Konemann EW, Allen SD, Dowell VR, Sommers HM. Diagnóstico Microbiológico - Texto e Atlas Colorido. $2^{\text {a }}$ Ed., São Paulo, Medicina Panamericana Editora do Brasil Ltda, 1993.

6. Joly, AB. Botânica - Introdução à taxonomia vegetal. USP, São Paulo, 1967.

7. Lorenzi H. Árvores Brasileiras. Piracicaba, São Paulo, Ed. Plantarium Ltda, 1992.

8. Marangoni DV. Staphylococcus aureus. In: Infeç̧ões Hospitalares - Prevenção e Controle. São Paulo, Ed. Savier, 1996, p.573-587.

9. Mian H, Pimenta FC, Tirapelli C, Zanin FR, Sanches K, Ito IY. Staphylococcus aureus: detecção de penicilinase das cepas isoladas da saliva de indivíduos saudáveis. In: Anais da $16^{\text {a }}$ SBPqO, 1999, p.106, \# B019.

10. NCCLS - National Committee for Clinical Laboratory Standards. 1998. In: Methods for dilution antimicrobial susceptibility tests for bacteria that grow aerobically. Villanova, PA: National Committee for Clinical Laboratory Standards, Publication M7-T.

11. Rizvi HA, Yasmeen A, Modan M, Badar Y. Screening of higher plants for antibacterial activity. Pakistan. J Sci Ind Res 30:215-220, 1987.

12. Samy RP, Ignacimuthu S. Sem A. Screening of 34 indian medicinal plants for antibacterial properties. J Ethonopha 62:183-193, 1998.

13. Silva IG, Santos AH, Ferri PH, Alves RBN, Melo RL, Peixoto L, Silva HHG, Elias CN, Isac E, Lira KS, Camargo MF. Ação larvicida de extrato bruto etanólico de Magonia pubescens St.Hil. (tingui-do-Cerrado), sobre o Aedes aegypti (Lin.) em laboratório. Rev Pat Trop 25:51-59, 1996.

14. Silva SC. Avaliação da atividade antimicrobiana in vitro de algumas espécies de Ipomoea. Dissertação de Mestrado - Faculdade de Ciências Farmacêuticas de Ribeirão Preto da Universidade de São Paulo, 1992. p.202.

15. Steers E, Foltz EL, Graves VS. An inocula replicating apparatus for continue testing of bacterial susceptibility to antibiotics. Antibio Chemother 9: 307-311, 1959.

16. Vaidya AB. Terminalia arjuna in cardiovascular therapy. $J$ Assoc Phys Ind 42:281-282, 1994. 